\title{
PET Fronteiras: uma trajetória que emerge da diversidade social e cultural, pautando os saberes e as práticas populares ${ }^{1}$
}

\author{
PET Fronteras: una trayectoria que emerge de la diversidad social y \\ cultural, pautando los saberes y las prácticas populares \\ PET Borders: a trajectory that emerges from the social and cultural \\ diversity, guided the popular knowledge and practices
}

\author{
Bruna Borges Rodrigues ${ }^{2}$ \\ Denise Marcos Bussoletti ${ }^{3}$
}

\begin{abstract}
Resumo
Esse trabalho pretende expor como o PET Fronteiras surge, seus princípios, como e por quem é formado e como realizamos nossas ações que visam uma educação voltada para a cultura e diversidade, dentro dos saberes e práticas populares. O PET Fronteiras trabalha nos marcos daquilo que os Estudos Culturais compreendem como sendo de uma Pedagogia da Fronteira, visando a troca de conhecimentos entre as comunidades populares urbanas e a universidade, buscando a formação de conhecimentos em suas manifestações. Nesse sentido, tomamos as ações desenvolvidas através do projeto "Crianças e Borboletas", como forma de reflexão de nossas ações. Nosso objetivo se pauta em apresentar como o PET Fronteiras surge e as problemáticas que o envolvem, elencando um projeto específico para tematizar o modo como realizamos suas ações.
\end{abstract}

Palavras-Chave: Cultura; Diversidade; Educação; Fronteira; PET.

\section{Resumen}

Este trabajo pretende exponer cómo el PET Fronteras surge, sus principios, cómo y por quién es formado, y cómo realizamos nuestras acciones que apuntan a una educación volcada a la cultura y la diversidad, dentro de los saberes y prácticas populares.. El PET Fronteras trabaja en los marcos de lo que los Estudios Culturales comprenden como de una Pedagogía de la Frontera, visando el intercambio de conocimientos entre las comunidades populares urbanas y la universidad, buscando la formación de conocimientos en sus manifestaciones. En ese sentido, tomamos las acciones desarrolladas a través del proyecto "Niños y Mariposas", como forma de reflexión de nuestras acciones. Nuestro objetivo es guiado a presentar como el PET Fronteras surge y las problemáticas que lo envuelven, enumerando un proyecto específico para tematizar el modo en que realiza sus acciones.

\footnotetext{
${ }^{1}$ Esse artigo faz parte de um resumo intitulado "Dialogando entre Fronteiras: Os Saberes e as Práticas Populares dentro do Programa de Educação Tutorial", enviado e aceito no Congresso de Ensino de Graduação da Universidade Federal de Pelotas, que será realizado entre os dias 20 a 24 de novembro de 2017, sob a seguinte autoria: RODRIGUES, Bruna B.; MELLO, Renata B.; KOHLS, Tatiane M. e BUSSOLETTI, Denise M. Aqui apresentaremos esse resumo de forma estendida, com novos dados, refletindo sobre o processo de criação do PET Fronteiras e a forma como articulamos nossas ações através das práticas e saberes populares.

${ }^{2}$ Graduanda em Ciências Sociais Bacharelado; Bolsista do PET Fronteiras - Saberes e Práticas Populares; Universidade Federal de Pelotas; Pelotas, Rio Grande do Sul, Brasil; brubsrodriguesr13@gmail.com.

${ }^{3}$ Doutora em Psicologia; Professora do Programa de Pós-Graduação em Educação; Tutora do PET Fronteiras Saberes e Práticas Populares; Universidade Federal de Pelotas; Pelotas, Rio Grande do Sul, Brasil; denisebussoletti@gmail.com.
} 
Palabras claves: Cultura; Diversidad; Educación; Fronteras; PET.

\section{Abstract}

This work aims to expose how the PET Borders emerges, its principles, how and by whom it is formed and how we carry out our actions aimed at an education for culture and diversity within the popular knowledge and practices. The PET Borders works in the framework of what cultural studies comprise to be a Border Pedagogy, aimed at exchange of knowledge between urban poor communities and universities, seeking the formation of knowledge in their manifetations. In this sense, we take the actions developed through the "Children and Butterflies" project, as a way of reflecting our actions. Our objective is to show how PET Borders arises and the problems that surround it, listing a specific project to thematic the way we carry out its actions.

Keywords: Culture; Diversity; Education; Border; PET.

\section{Introdução}

O PET Fronteiras faz parte do Programa de Educação Tutorial - Conexões e Saberes desenvolvido pelo Ministério da Educação e sustenta suas ações em uma proposta de educação voltada à diversidade social e cultural e ao respeito aos direitos humanos com princípios, trabalha nos marcos daquilo que os Estudos Culturais compreendem como sendo o de uma Pedagogia da Fronteira, visando ainda à troca de conhecimentos entre as comunidades populares urbanas e a universidade (BUSSOLETTI; VARGAS, 2014; KOHLS; et al, 2016; MARTINS; et al, 2016).

O conceito de fronteira, segundo Bussoletti e Vargas (2014, p. 42) é "um elemento fundamental para pensarmos em propostas pedagógicas que abarquem as diferenças como um foco de aprofundamento ao enriquecimento da produção do conhecimento em sua ampla complexidade". Sendo que é nesse conceito de pedagogia da fronteira que se fomentam as propostas pedagógicas do grupo, abarcando as diferenças como práticas educativas e emancipatórias dentro do cenário educativo brasileiro.

Nesse sentido, especificamente enfocando as ações do PET Fronteiras, elencamos uma de nossas ações, o projeto "Crianças e Borboletas" (RODRIGUES; et al 2016), apresentando parte das principais reflexões que emergem de nossas ações, tomando a experimentação artística como condição de um fazer educativo pelos caminhos da diversidade social e cultural. Assim, exemplificando como o PET Fronteiras realiza os seus pressupostos através das práticas e saberes populares.

\section{Contextualizando a origem do Programa de Educação Tutorial Fronteiras: Saberes e Práticas Populares}

O Programa de Educação Tutorial surge através da Lei 11.180/2005, sendo regulamentado pelas Portarias n 976/2010 e n 343/2013 do Ministério da Educação (MEC) e pela Resolução FNDE no 36.201/2009. Como aponta o Manual de Orientações Básicas - 
MOB (2006), o PET foi criado em 1979 pela Coordenação de Aperfeiçoamento de Pessoal de Nível Superior (CAPES), com o nome de Programa Especial de Treinamento - PET, sendo assim transferido em 1999 para a Secretaria de Educação Superior do Ministério da Educação sob gestão do Departamento de Mobilização e Programas da Educação Superior (DEPEM) e, somente em 2004 passou a chamar Programa de Educação Tutorial (MINISTÉRIO DE EDUCAÇÃO, 2006).

O PET é formado por estudantes, com tutoria de um/uma docente, sendo orientado pelo princípio da indissociabilidade entre ensino, pesquisa e extensão. Segundo o MEC, atualmente o PET conta com 842 grupos distribuídos entre 121 Instituições de Ensino Superior (MINISTÉRIO DE EDUCAÇÃO, 2006), sendo 15 deles alocados na UFPel, com 12 sendo PET's ligados à cursos de graduação e 3 PET's temáticos, os quais englobam divergentes cursos oriundos da universidade, enfatizando a interdisciplinaridade, denominados PETs Institucionais, como já dito anteriormente é a classificação do PET Fronteiras. De acordo com MOB (2006), somente são mencionados grupos vinculados a um curso de graduação, o que é hegemônico na realidade Petiana.

De acordo com o MOB (2006), os objetivos do programa PET se caracterizam como:

A constituição de um grupo de alunos vinculados a um curso de graduação para desenvolver ações de ensino, pesquisa e extensão sob a orientação por um professor tutor visa oportunizar aos estudantes participantes a possibilidade de ampliar a gama de experiências em sua formação acadêmica e cidadã (MOB, 2006, item 1.1, p. 06).

Ressaltamos que objetivo geral do PET Fronteiras é tematizar os saberes e as práticas populares focalizando a produção de conhecimentos verificados através das manifestações culturais que se desenvolvem nas comunidades populares urbanas articulando com os conhecimentos produzidos na universidade. (PROGRAMA DE EDUCAÇÃO TUTORIAL PET FRONTEIRAS, 2012). Desse modo o PET Fronteiras segue e cumpre a orientação nacional do PET que possui como foco

[...] o trabalho com comunidades populares urbanas, campo, quilombola ou indígenas, voltados à diversidade social, constituído exclusivamente por bolsistas em condição de vulnerabilidade social e econômica, conforme critérios descritos no item 4.3.1 deste edital, formados com no máximo 12 bolsistas, a serem selecionados de acordo com o art. 17 da Portaria MEC n ${ }^{\circ}$ 976. As propostas poderão ter escopo/abrangência interdisciplinar, institucional, de grande área do conhecimento ou vinculado a curso específico. (SECRETARIA DE EDUCAÇÃO SUPERIOR, 2012.) 
Sendo assim, se vinculam ao PET FRONTEIRAS os estudantes oriundos das comunidades populares urbanas e os em condição de vulnerabilidade social e econômica. Com isso, nos apoiamos no próprio PPI da UFPel para respondermos às problemáticas anteriormente levantadas, pois o PPI considera ainda que o profissional egresso das diversas áreas deve ser capaz de:

\begin{abstract}
a) agir dentro de um paradigma de meta-reflexão; b) pautar-se pelos princípios da ética, igualdade, respeito e democracia; c) ler a realidade na qual vai intervir e refletir sobre ela; d) propor soluções para os diversos problemas nessa realidade; e) juntar teoria e prática nas ações que visem à melhoria de vida do povo; f) trabalhar colaborativamente na criação de ações transformadoras (UNIVERSIDADE FEDERAL DE PELOTAS - PPI, 2003, p. 08).
\end{abstract}

Para tanto, é importante que façamos reflexões e ampliações no próprio conceito de ensino que, em nosso grupo, se alinha de forma indissociável entre pesquisa e extensão. Acreditamos que um processo de ensino se fortalece quando se articula com um princípio de extensão. A extensão é instrumentalizadora de um processo dialético entre teoria/prática e propicia um trabalho interdisciplinar que favorece a visão integrada do social. Esta relação entre o ensino e a extensão se caracteriza como uma via de mão-dupla, com trânsito entre a comunidade acadêmica, que encontrará, na sociedade, a oportunidade da elaboração e aplicação do conhecimento acadêmico, sendo que no retorno à universidade, docentes e discentes trarão um aprendizado que, submetido à reflexão teórica, será acrescido àquele conhecimento. Este fluxo, entre a troca de saberes sistematizados/acadêmico social, traz como consequência a produção de conhecimentos resultantes do confronto com os dilemas e necessidades da realidade brasileira, local e regional, a democratização do conhecimento acadêmico e a participação efetiva da comunidade na universidade e da universidade na sociedade.

\title{
3. Contextualizando o Projeto Crianças e Borboletas
}

Muitas são as ações e projetos desenvolvidos pelo PET Fronteiras ${ }^{4}$, perpassando pelo campo das artes e buscando sempre uma interlocução como a comunidade local. Nesse sentido, tomamos como reflexão de nossas ações o projeto Crianças e Borboletas, vinculado também ao Núcleo de Arte, Linguagem e Subjetividade (NALS) ${ }^{5}$ da Universidade Federal de Pelotas, situado na linha de pesquisa Infâncias e Narrativas.

\footnotetext{
${ }^{4}$ Outros projetos e ações desenvolvidas pelo grupo podem ser consultadas através do site oficial do PET Fronteiras em < http://pet-saberes-e-praticas-populares1.webnode.com/>.

${ }^{5}$ Mais informações sobre o NALS podem ser acessadas no site: < http://nals-ufpel.webnode.com/>.
} 
O projeto Crianças e Borboletas visa problematizar a intolerância na história localizando no acontecimento do holocausto uma expressão maior desta. Possui como matriz conceitual e metodológica parte da tese de Bussoletti (2007), partindo da hipótese da qual partilhamos, que afirma que existe um processo de "holocaustização" da infância expresso de diferentes formas na contemporaneidade. Tal pesquisa de tese tomou como objeto de análise os desenhos e os poemas das crianças que viveram e morreram no gueto de Terezin, situado a $60 \mathrm{~km}$ da cidade de Praga durante a segunda guerra mundial. É importante salientar que no gueto de Terezin ingressaram cerca de 15 mil crianças, sendo que destas somente 100 retornaram vivas no pós-guerra. Durante o período em que estas crianças estiveram prisioneiras elas produziram uma série de desenhos e poemas que ao final da segunda guerra mundial foram organizados pelo Museu Judaico de Praga e que após 1996 percorreram o mundo através de uma mostra intitulada I never saw another butterfly.

Partindo dessa ideia, o projeto Crianças e Borboletas compartilha da hipótese de que existe um processo de "holocaustização das infâncias" que não pode ser somente circunscrito ao contexto da segunda guerra mundial, engendramos um conjunto de ações e práticas reflexivas e de intervenção social em diversas escolas periféricas da cidade de Pelotas/RS.

Compreendemos que o processo de barbárie engendrado pela sociedade capitalista deu e dá continuidade às políticas nem sempre visíveis de extermínio das infâncias na contemporaneidade. Neste sentido a proposta metodológica inclui a leitura de um poema intitulado "I never saw another butterfly" e o debate com as crianças. Este processo prevê as técnicas de contação de histórias e/ou dramatização e a expressão plástica através da confecção de desenhos. O objetivo final dessas ações é o de erguer um debate utilizando a infância como uma alegoria contra o processo de holocaustização pedagógica e social vigente. Os desenhos produzidos durante as oficinas do projeto Crianças e Borboletas, nos possibilitam a aproximação, permeando esse espaço entre a poética, o real e o lúdico. A proposta pretende apontar na direção de uma Educação sensível e que pela experiência do testemunho se consolide como um projeto crítico e alternativo. O projeto ainda está em andamento e o aprofundamento teórico caminha em paralelo com a prática e a experimentação que o universo infantil nos remete e implica.

Nessa perspectiva, através da experimentação artística buscamos um fazer educativo e sensível voltado a diversidade cultural e social. É através das narrativas que surgem a partir da visão das crianças que refletimos e articulamos as práticas e saberes populares encontrados nas periferias de Pelotas. 
Como mencionado anteriormente, a proposta do projeto Crianças e Borboletas pretende apontar na direção de uma Educação sensível que, pela experiência do testemunho, se consolide como um projeto crítico e alternativo. Isso porque compreendemos que na atualidade a palavra educação é, muitas vezes, apropriada por um projeto colonial de formação do humano que se restringe a reproduzir a "colonialidade" do saber, do ser e do poder, através de uma conjuntura marcada pela racionalidade técnico-instrumental de uma globalização neoliberal, ancorada no individualismo, na homogeneização cultural e na monetarização da vida (FIGUEIREDO; ANDRIOLI; FRANTZ, 2013), com a finalidade de reproduzir o status quo. Compreendemos que romper com essa lógica capitalista é uma tarefa árdua, mas não impossível, diante da concepção de que “[...] o que existe na vida social está em perpétua transformação, tudo é perecível, tudo está sujeito ao fluxo da história.” (LÖWY,1989) e assim, buscamos confrontar a realidade, problematizando a intolerância na história - tendo o holocausto como uma expressão maior desta, onde infância pode emergir como meio de denúncia da barbárie imposta pela lógica do sistema capitalista, e pela qual pode-se anunciar um outro mundo possível.

Sendo assim, é a partir de uma troca, entre a universidade e a comunidade, que o PET Fronteiras promove debates em torno do respeito, da diversidade, da cultura e o conhecimento dos saberes e práticas populares dentro do espaço educativo.

\section{Pensar as práticas educativas através da fronteira - através da janela}

A Fronteira como pressuposto pedagógico do PET Fronteiras se baseia através daquilo que os estudos culturais definem como uma pedagogia da fronteira (Giroux, 1992), ou ainda no que Mclarem (2000) denominou como sendo uma identidade de fronteira, criadas a partir da empatia [...] como forma de uma conexão passional através da diferença na luta contra a nossa falha em ver nosso próprio reflexo nos olhos dos outros" (MCLAREM, 2000, p.194-195). O conceito de fronteira, segundo Bussoletti e Vargas (2014, p. 42) é "um elemento fundamental para pensarmos em propostas pedagógicas que abarquem as diferenças como um foco de aprofundamento ao enriquecimento da produção do conhecimento em sua ampla complexidade". Sendo que é nesse conceito de pedagogia da fronteira que se abarcam as diferenças como práticas educativas e emancipatórias dentro do cenário educativo brasileiro.

No entanto, existe a necessidade de pontuarmos que alguns autores (BHABHA, 1998:63; BUSSOLETTI, 2012; VARGAS, 2012) trazem importantes reflexões sobre a diversidade e a diferença dentro do aspecto das práticas educativas, compreendendo que os 
princípios pedagógicos de uma educação voltada à diversidade podem oferecer condições de implementação de práticas emancipatórias efetivas no cenário social e educativo brasileiro

[...] os embates acerca da diversidade e da diferença, as políticas públicas brasileiras se inscrevem em um cenário que é impulsionado pelo marco expressivo estabelecido pela Constituição Federal de 1998 (...), que entre seus fundamentos postula a dignidade humana e os direitos ampliados da cidadania consagrando o debate que corre principalmente desde os anos 1980 no Brasil sobre o respeito à diversidade cultural no sentido de formação para a cidadania. Desde então, vários mecanismos surgiram no cenário nacional e internacional na perspectiva da promoção e da defesa dos direitos humanos. (BUSSOLETTI; VARGAS, 2012. pag. 15)

Para tanto, é importante ressaltar de qual conceito de diversidade estamos falando e, principalmente, fazer a distinção entre diversidade e diferença. Segundo Homi Bhabha (1998:63), diversidade cultural é um objeto epistemológico, onde a cultura é apreendida como objeto do conhecimento empírico, já a diferença é um processo de enunciação da cultura como "conhecível", legítimo, adequado à construção de sistemas de identificação cultural, sendo assim

\footnotetext{
um processo de significação onde a cultura se afirma como um campo de forças onde os diferentes grupos afirmam e reconhecem sua própria identidade, nunca homogênea, nem muito menos como representações de separação de culturas totalizadas ou protegidas na utopia de uma memória mítica de uma identidade coletiva única (BUSSOLETTI; VARGAS, 2012. Pg. 15)
}

Segundo alguns estudos (BUSSOLETTI; VARGAS, 2012), no contexto de proposição de políticas afirmativas e de inclusão social, as políticas públicas brasileiras vêm pautando também o discurso da diversidade através dos eixos da organização social e de políticas necessárias e sua viabilização, o que julgamos ser de suma importância, uma vez que que o discurso neoliberal na sociedade e, em consequência, na educação encontra-se fortalecido; que a educação em síntese, tanto pode legitimar ou transformar, oprimir ou libertar.

Ao tocarmos na temática da educação, parece-nos relevante fazer uma breve e poética ligação entre a educação e uma janela. A educação, assim como a janela, quando fechada, torna-se apenas um somatório do ambiente, por onde não nos é permitido ver o outro lado e com isso, torna-se difícil construir uma visão contundente da realidade e, tanto a educação quanto a janela, quando fechadas, acabam por deixar de cumprir o seu real papel - o de conectar o lado de lá com o lado de cá, o de trazer a realidade e à realidade. O papel de mostrar os horizontes possíveis. 


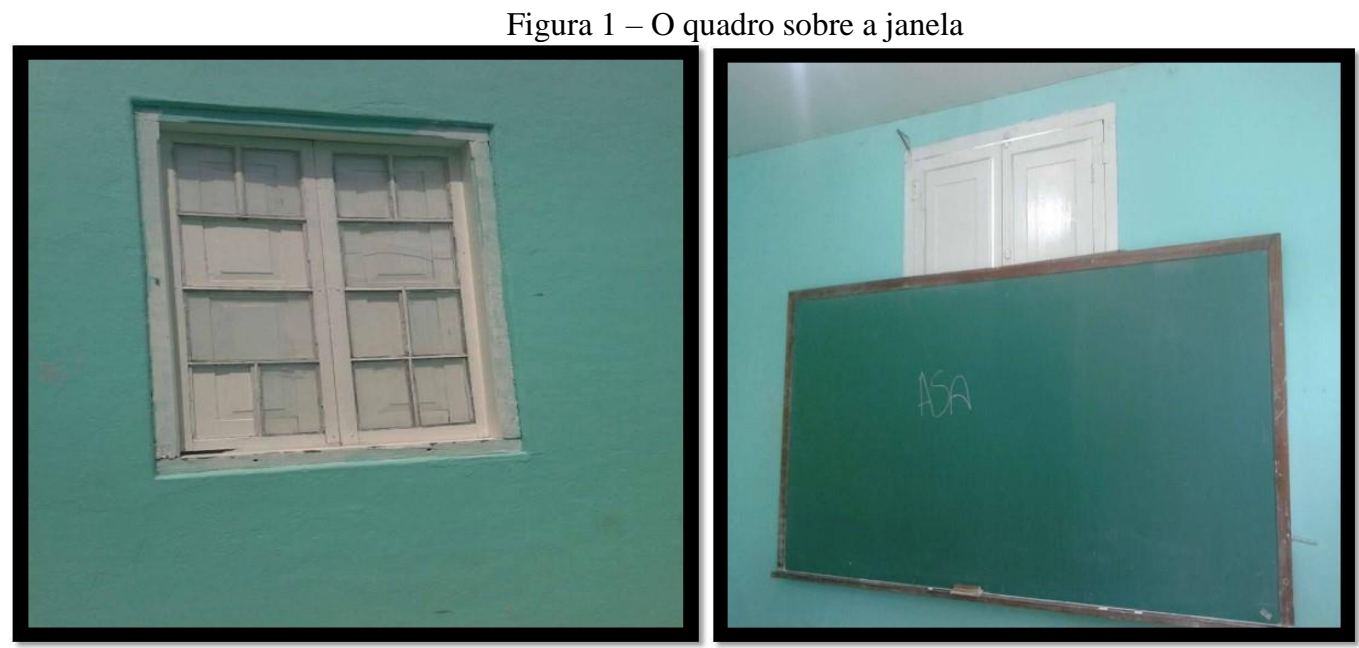

Fonte: Acervo PET/NALS 2017

"[...] Há só uma janela fechada, e todo o mundo lá fora; E um sonho do que se poderia ver se a janela se abrisse, Que nunca é o que se vê quando se abre a janela." - Fernando Pessoa

Usamos a fotografia do quadro sobre a janela - registrada em uma de nossas ações em uma escola da rede municipal de ensino em Pelotas/RS, como mostra Figura 1, por entendermos que na fotografia existe algo que não pode ser silenciado - o que se põe nela é a realidade, uma realidade, segundo Benjamin (1994) onde a natureza que fala à câmera não é a mesma que fala ao olhar; é outra, especialmente porque substitui a um espaço trabalhado conscientemente por nós, sendo o mesmo espaço que nós percorremos inconscientemente. Por isso, convidamos a todos educadores e educadoras, educandos e educandas, a ousarem abrir essa janela, para que ela volte a nos conectar com a realidade e com isso, a educação enquanto janela aberta, afirme cada vez mais que o conhecimento se constrói nas trocas e olhares constantes e diferentes, na troca frequente de saberes-horizontes.

Assim, evidenciamos que as fronteiras - assim como o olhar-através-da-janela, são vivenciadas de maneiras essencialmente diferentes: por dentro, na auto consciência e por fora no vivenciamento estético do outro e, com isso, sustentamos que as fronteiras se movimentam, e é exatamente nesse movimento que se pode notar a existência de diferentes maneiras de vivenciar a fronteira - assim como as diferentes maneiras de olhar-através-dajanela. 


\section{Conclusões}

Acreditamos que, ao propor essas reflexões, expomos pressupostos do Programa de Educação Tutorial - PET Fronteiras: Saberes e Práticas Populares, ressaltando a necessidade de realização de um processo dialético no que diz respeito à produção do conhecimento científico através do Programa de Educação Tutorial. Ao tematizar os saberes e as práticas populares, enfrentamos alguns embates que nos fazem problematizar a formação que o Programa PET de forma geral vem desenvolvendo. Defendemos que, principalmente no contexto de dificuldades em que as Universidades públicas se encontram, o ensino assuma um papel político, justamente por fazer parte da formação profissional e cidadã dos atores envolvidos. Para tanto, o ensino em um PET - seja ele de curso ou institucional, faz parte de um contexto que o justifica, pois, o conhecimento não deixa de ser conhecimento científico se não for vinculado a um curso único e específico de graduação. Notadamente verificamos a contradição existente e a marginalização ou não compreensão da importância de um PET institucional nos espaços acadêmicos. É necessário refletir de forma coletiva sobre como esta relação vem se verificando.

Ressaltamos que o PET Fronteiras através de uma atuação qualificada no ensino, pesquisa e extensão, é um dos importantes espaços pedagógicos na UFPel que nos possibilita aliar a formação recebida, técnica e científica, às necessidades, aos saberes e as práticas das comunidades populares envolvidas, assumindo como um de seus princípios a formação de estudantes críticos, comprometidos e conscientes de seu papel político e cidadão e, somado à isso reafirmamos o papel importante que projetos como o "Crianças e Borboletas" assumem em nossa sociedade, no sentido do questionamento acerca sobre o lugar da infância, suas representações, sendo este um caminho fértil que poderá nos permitir ampliar não somente o papel da educação hoje, como também pelas e através das crianças tratar de questões acerca da intolerância em nossos dias.

\section{Referências}

BENJAMIN, W. Magia e técnica, arte e política: ensaios sobre literatura e história da cultura. (Obras Escolhidas) v. 1. São Paulo: Brasiliense, 1994.

BUSSOLETTI, Denise Marcos. Infâncias Monotônicas - Uma rapsódia da Esperança Estudo psicossocial cultural crítico sobre as representações do outro na escrita de pesquisa. Porto Alegre, 2007. Tese (Doutorado em Psicologia) - Pontifícia Universidade Católica do Rio Grande do Sul. 
BUSSOLETTI, Denise Marcos; VARGAS, Vagner de Souza. Por entre fronteiras de uma pedagogia que pauta a educação pelas artes gingando saberes e práticas populares.

Extraprensa, São Paulo, ano 8, nº 4, p. 41 - 48, 2014.

BUSSOLETTI, D.; VARGAS, V. Leituras em Dramaturgia teatral para a diversidade. Pelotas, Editora Universitária UFPel, 2012.

BHABHA, H. O local da cultura. Belo Horizonte: Ed. UFMG, 1998

CATÁlogo do MUSEU JUdAICO DE PRAGA. No He Visto Mariposas Por Aqui. Tiskana Flora, 1996.

FIGUEIREDO, J.; ANDRIOLI, L.; FRANTZ, W. Educação Popular no contexto da globalização neoliberal. Revista Educação em Questão, Natal, v. 47, n 33, p. 86-108, set./dez. 2013

GIROUX, Henry. Teoria Crítica e Resistência em Educação. Para além das teorias de reprodução. Tradução de Ângela Maria B. Biaggio. Petrópolis: Vozes, 1986

KOHLS, T.M.; BARBOSA, R.D.; MARTINS, F.S; BUSSOLETTI, D.M. PET

FRONTEIRAS - Saberes e Práticas Populares: uma proposta pautada na diversidade social e cultural. Conexões Culturais - Revista de Linguagens, Artes e Estudos em Cultura, v. 2, p. 48$55,2016$.

LÖWY, Michael. Ideologias e ciência social: elementos para uma análise marxista. 5. ed. São Paulo: Cortez, 1989.

MCLAREN, P. Multiculturalismo crítico. São Paulo: Cortez, 2000.

MINISTÉRIO DE EDUCAÇÃO, BRASIL. Programa de Educação Tutorial - PET: Manual de Orientações. Brasília, 2006. Acessado em 12 out. 2017. Online. Disponível em:

http://portal.mec.gov.br/pet/manual-de-orientacoes.

MINISTÉRIO DA EDUCAÇÃO - FUNDO NACIONAL DE DESENVOLVIMENTO DA EDUCAÇÃO. Acessado em 12 out 2017. Disponível em:

https://www.fnde.gov.br/fndelegis/action/UrlPublicasAction.php?acao=getAtoPublico\&sgl_ti po $=$ RES \&num_ato $=00000036 \&$ seq_ato $=000 \& v l r \_a n o=2009 \& \operatorname{sgl} \_$orgao $=C D \% 2 F F N D E \% 2 F$ MEC.

PLANALTO. LEI No 11.180, DE 23 DE SETEMBRO DE 2005. Acessado em 12 out 2017. Disponível em: http://www.planalto.gov.br/ccivil_03/_ato2004-2006/2005/lei/111180.htm.

PROGRAMA DE EDUCAÇÃO TUTORIAL - PROJETO PET FRONTEIRAS: Saberes e Práticas Populares, Universidade de Federal de Pelotas, 2012. Acessado em 12 out. 2017. Disponível em: http://pet-saberes-e-praticas-populares1.webnode.com/projeto-pet-fronteiras/.

PROGRAMA DE EDUCAÇÃO TUTORIAL. Universidade de Federal de Pelotas, 2012. Acessado em 12 out. 2017. Disponível em: http://wp.ufpel.edu.br/prg/programas/pet/. 
RODRIGUES, B. B.; KOHLS, T M.; BUSSOLETTI, D.M. Apresentado o projeto Crianças e Borboletas. In: Anais do $3^{\circ}$ Congresso de Extensão e Cultura da UFPel, 26 à 30 setembro em Pelotas./Organizado por Denise Bussoletti, Evandro Piva, Carlos Oliveira. - Pelotas: Editora da UFPel, 2016. p. 60-63. Acessado em: 20 out. 2017. Disponível em:

http://wp.ufpel.edu.br/congressoextensao/files/2016/12/EDUCA\%C3\%87AO-2016-.pdf.

SECRETARIA DE EDUCAÇÃO SUPERIOR. EDITAL Nº 11, DE 19 DE JULHO DE 2012 PROGRAMA DE EDUCAÇÃO TUTORIAL. Acessado em 12 out. 2017. Disponível em: http://portal.mec.gov.br/index.php?option=com_docman\&view=download\&alias=11219edital-pet-11-190712-pdf\&category_slug=julho-2012-pdf\&Itemid=30192 .

SISTEMA DE GESTÃO DO PROGRAMA DE EDUCAÇÃO TUTORIAL. Portarias disponibilizadas no site do SIGPET. Acessado em 12 out 2017. Disponível em: http://sigpet.mec.gov.br/primeiro-acesso.

UNIVERSIDADE FEDERAL DE PELOTAS. Projeto Pedagógico Institucional. Pelotas, 2003. Acessado em 12 out. 2017. Online. Disponível em: https://wp.ufpel.edu.br/pdi/ppiprojeto-pedagogico-institucional/. 